\title{
Considerações sobre a estrutura de uma Pesquisa Qualitativa - como ler e como planejar um estudo qualitativo
}

\author{
Simone de Oliveira Camillo ${ }^{1}$ \\ 'Editora Adjunta - E-mail: si.camillo@uol.com.br
}

DOI: https://doi.org/10.7322/abcshs.v43i2.1187

As pesquisas qualitativas, nas últimas décadas, tornaram-se bem aceitas pelos jornais médicos. Felizmente, hoje, muitas revistas científicas publicam pesquisas qualitativas de modo habitual. Isto não acontecia no passado. Os pesquisadores que utilizavam este tipo de estudo tinham os manuscritos rejeitados devido aos trabalhos serem considerados não-científicos. Entretanto, apesar da facilidade de encontrar profissionais de saúde que dão importância aos métodos qualitativos e reconhecem sua ajuda para melhor compreender os fenômenos, não significa, necessariamente, que estes métodos estejam bem compreendidos e utilizados por eles ${ }^{1}$.

Dessa forma, faz-se necessário algumas considerações sobre a estrutura de uma investigação qualitativa, trazendo aos leitores elementos essenciais para a sua apresentação.

Este texto é endereçado a leitores e consumidores destas produções científicas para maior clareza de critérios no julgamento da pertinência do caminho percorrido pelos estudiosos deste tipo de método. Além disso, também pode fornecer subsídios aos que pretendem elaborar seus projetos de investigação qualitativa, para que o façam no rigor científico esperado.

Os pontos essenciais para a construção de um artigo nesta modalidade de pesquisa abrangem todos os seus componentes tradicionais: título, resumo, introdução, objetivo, método, resultados e conclusões.

O título da pesquisa deve refletir o conteúdo do trabalho, sendo conciso e pertinente. $\mathrm{O}$ resumo deve ser descrito adequadamente ao conteúdo do trabalho contemplando os objetivos, metodologia, resultados e as considerações finais. Assim como os descritores devem estar de acordo com o conteúdo do trabalho e com os Descritores em Ciências da Saúde.

$\mathrm{Na}$ introdução deve-se conter a problemática, o objeto de estudo, a questão norteadora, a justificativa e a revisão da literatura. Estes elementos fundamentais devem ser apresentados em uma sequência lógica no desenvolvimento da temática, mencionando a relevância prática quanto aos aspectos teóricos e/ou de aplicação. O objetivo do estudo deverá ser expresso com exatidão ao que foi investigado.

O método deverá ser escrito com clareza, descrevendo o referencial teórico filosófico com pertinência e profundidade. Toda pesquisa qualitativa necessita de um referencial teórico filosófico, ou seja, a utilização de teóricos para apoiar ideias e concepções dentro de um trabalho. Um projeto de pesquisa bem fundamentado deve apresentar o referencial teórico que norteará a proposta, os objetivos e os procedimentos que serão realizados. As funções que cumpre o referencial teórico são: sustentar e orientar teoricamente o estudo, ampliar o horizonte do estudo e guiar o investigador, definindo de onde será visto o problema. Um exemplo do uso do referencial teórico para falarmos sobre o desenvolvimento infantil. Se escolhermos John Bowlby, falaremos a partir do princípio que um recém-nascido precisa desenvolver um relacionamento com pelo menos, um cuidador primário para que seu desenvolvimento social e emocional ocorra normalmente $^{2}$. Se falarmos a partir de Henri Wallon, o mesmo dirá que o desenvolvimento infantil se dará por meio de quatro elementos básicos que se comunicam o tempo todo, a afetividade, o movimento, a inteligência e a formação do eu como pessoa ${ }^{3}$.

No método deve constar a descrição dos sujeitos, a justificativa do número de sujeitos, critérios de inclusão e exclusão.

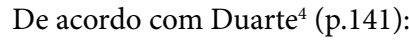

"De um modo geral, pesquisas de cunho qualitativo exigem a realização de entrevistas, quase sempre longas e semi-estruturadas. Nesses casos, a definição de critérios segundo os quais serão selecionados os sujeitos que vão compor o universo de investigação é algo primordial, pois interfere diretamente na qualidade das informações a partir das quais será possível construir a análise e chegar à compreensão mais ampla do problema delineado. A descrição e delimitação da população base, ou seja, dos sujeitos a serem entrevistados, assim como o seu grau de representatividade no grupo social em estudo, constituem um problema a ser imediatamente enfrentado, já que se trata do solo sobre o qual grande parte do trabalho de campo será assentado. Numa metodologia de base qualitativa o número de sujeitos que virão a compor o quadro das entrevistas dificilmente pode ser determinado a priori - tudo depende da qualidade das informações obtidas em cada depoimento, assim como da profundidade e do grau de recorrência e divergência destas informações. Enquanto estiverem aparecendo 'dados' originais ou pistas que possam indicar novas perspectivas à investigação em curso as entrevistas precisam continuar sendo feitas." 
Ainda no método deve constar o processo e o período de coleta de dados, o instrumento utilizado e o método de análise de dados. Os instrumentos de coleta de dados não devem ser norteados por perguntas fechadas. Trabalhos onde são encaixadas simples citações literais de falas de sujeitos que responderam a questionários previamente padronizados não configuram pesquisa qualitativa.

As pesquisas qualitativas são caracterizadas pelo uso da técnica de análise de conteúdo (dentre outras). Dessa forma, nos resultados não cabe a caracterização de dados numéricos, percentual absoluto ou tabelas. Os resultados devem ser apresentados pelo uso de observações do campo e/ou citações literais. Os resultados devem ser pertinentes aos achados. Assim, como a discussão deve apresentar argumentação consistente e ampla, respondendo aos objetivos do estudo e ao referencial teórico adotado.

Os princípios éticos da pesquisa deverão estar descritos, assim como a referência à assinatura do Termo de Consentimento Livre e Esclarecido e ou assentimento (crianças e adolescentes) pelos participantes do estudo. Indicando o número do parecer de aprovação do estudo por Comitê de Ética em Pesquisa Envolvendo Seres Humanos.

Nas considerações finais, a questão norteadora do estudo e/ ou os objetivos deverão ser respondidos. Também deve constar no artigo referência à aplicação dos resultados nas práticas em saúde, nas áreas de ensino, pesquisa, assistência e gestão. É fundamental que as limitações do estudo sejam contempladas, assim como a sugestão de novas pesquisas, com a finalidade de aprofundar os resultados apresentados no atual trabalho que será publicado.

Os aspectos mencionados são fundamentais para a qualidade de um artigo qualitativo. No passado, desatenção e desinformação em relação a estes itens resultaram em defeitos no planejamento e na apresentação de estudos qualitativos, possivelmente contribuindo para o preconceito que existia. O presente texto teve por finalidade apresentar boas práticas para execução e avaliação de estudos qualitativos, e assim colaborar para o desenvolvimento e a maturidade desta metodologia.

\section{REFERÊNCIAS}

1. Turato ER. Métodos qualitativos e quantitativos na área da saúde: definições, diferenças e seus objetos de pesquisa. Rev Saúde Pública. 2005;39(3):507-14.

http://dx.doi.org/10.1590/S0034-89102005000300025

2. Bowlby J. Attachment. 2ed. Basic books; 2008.
3. Wallon H. A evolução psicológica da criança. Martins Fontes: 2007.

4. Duarte R. Pesquisa qualitativa: reflexões sobre o trabalho de campo. Cad Pesqui. 2002:(115):139-54. http://dx.doi.org/10.1590/S0100-15742002000100005 